\title{
Vestibular rehabilitation therapy in elderly with benign paroxysmal positional vertigo
}

\begin{abstract}
The vestibular system contributes to the maintenance of the bipedal posture and balance. Peripheral vestibular alterations such as paroxysmal positional benign vertigo have high prevalence in elderly, being responsible for a large number of falls, which can cause disability and death. It has been shown that repositioning maneuvers and physical therapy aimed at restoring balance have good results in reducing symptoms, and also improve the quality of life of elderly.
\end{abstract}

Keywords: elderly, falls, balance, vestibular system, vestibular rehabilitation therapy
Volume 5 Issue I - 2020

\author{
Yeny Concha-Cisternas, ${ }^{1,2}$ Eduardo Guzmán- \\ Muñoz' \\ 'Escuela de Kinesiología, Facultad de Salud, Universidad Santo \\ Tomás, Chile \\ ${ }^{2}$ Pedagogía en Educación Física, Facultad de Educación, \\ Universidad Autónoma de Chile, Chile
}

Correspondence: Yeny Concha Cisternas, Escuela de Kinesiología, Facultad de Salud, Universidad Santo Tomás, Chile, Email yenyf.concha@gmail.com

Received: December 14, 2019 | Published: January 10, 2019

\section{Vestibular system}

Postural balance is ensured by three systems that capture inputs from the external environment: vision, proprioception and vestibular. The inputs captured by these systems are sent to the Central Nervous System (CNS), where they are examined, compared and integrated. ${ }^{1,2}$ Of these systems, the vestibular system participates as a tool to maintain control of posture and balance when the person is standing and during locomotion.

The four most important roles of the vestibular system in postural control are: perception of body position and self-movement, orienting the body vertically using sensory orientation, controls the position of the center of the body in static or dynamic positions, and finally stabilizing the head during postural movements. ${ }^{3}$ When the inputs provided to the nervous centers are not coherent with each other because of a damage at any of these structures, whether peripherical or central, a sensorial conflict occurs, leading to dizziness our postural imbalance. $^{2}$

Today, vestibular problems of peripheral origin constitute one of the most prevalent conditions in elderly due to the physiological functions being altered over the years. ${ }^{4}$ These alterations are accompanied by imbalance, vertigo, dizziness, spatial disorientation, visual problems, changes in hearing, psychological and cognitive changes, which can have an impact on functionality, autonomy and quality of life. ${ }^{5}$

\section{Peripheral vestibular disorders}

They are lesions of the peripheral sensory organ or nerve pathways until they reach the brainstem. ${ }^{2}$ Elderly may suffer from any peripheral vestibular disorder but benign paroxysmal positional vertigo (BPPV) is the most frequent.

\section{Benign paroxysmal positional vertigo (BPPV)}

The BPPV It is the most frequent type of peripheral vertigo, and the most prevalent over the years, reaching $25 \%$ in over 70 years (6). It is a clinical syndrome characterized by a history of positional vertigo and by positional nystagmus (generally torsional with a vertical component) elicited by a head-hanging maneuver usually called the Dix-Hallpike maneuver. ${ }^{6,7}$ Sometimes it is also associated with nausea, vomiting, paleness and sweating. ${ }^{6} \mathrm{BPPV}$ is the most common cause otoneurological conditions that has the highest prevalence in the geriatric population, leading to strong impact on the health and quality of life of these individuals. ${ }^{5}$

Its etiology is generally idiopathic (58\%), followed by head trauma $(6 \%-18 \%)$ and finally by diseases of the inner ear that include infections and inflammation or dysfunction of the inner ear microcirculation (3-9\%). ${ }^{8}$ Pathophysiologically in the BPPV, degeneration of the utricular macula, and otolithic detachment occur, and cupulolithiasis can be observed where otoliths travel through the semicircular canals from the utricle, and are deposited in the dome of the semicircular canals, or canalolithiasis, where otoliths are floating freely in the endolymphatic fluid within the semicircular canals, and these will move when the head is moved. ${ }^{9,10}$ Both phenomena occur more frequently in the posterior semicircular canal (80-96\%). ${ }^{10}$

Once the diagnosis of BPPV is established, it is suggested as a repositioning and release maneuver treatment plan, in addition to a vestibular rehabilitation program developed by a physiotherapist. ${ }^{6-11}$

\section{Vestibular rehabilitation therapy}

The vestibular rehabilitation therapy is an efficient physiological therapy method that acts in the vestibular system, potentiates the CNS's neuroplasticity, promotes postural balance recovery and stimulates the natural compensation, adaptation and habituation mechanisms. ${ }^{2,8}$ It is based on body exercise programs or specific physical maneuvers, associated to recommendations about habit changes. The exercises aim to improve the postural balance function and, consequently, improve the individual competent in the execution of everyday activities and reduce fall risk. ${ }^{5}$ Literature indicates that these maneuvers can be carried out by specialty-trained vestibular physiotherapist or the otolaryngologist. ${ }^{12}$

Among the specific repositioning techniques performed in the vestibular rehabilitation therapy for elderly are the Semon and Epley maneuvers, which have demonstrated greater effectiveness in reducing the patient's symptomatology. ${ }^{11,13}$ In 1988 Semont described what would be called the dome maneuver for cupulolithiasis. Semon maneuver involves moving the seated patient quickly from sitting to lying with the affected ear down, then quickly over so the other 
ear is down, and then back to the sitting position ${ }^{14}$ (Figure 1). While Epley in 1992 described the replacement maneuver for posterior semicircular canal canalithiasis. ${ }^{15}$ This manuver involves a 5 position cycle in which the patient's head is moved about in such a way as to displace theoretically any loose material in the posterior semicircular canal into the utricle of the vestibular labyrinth (Figure 2). Of both treatments, Epley maneuver is more gentle and easier to perform in a geriatric population. ${ }^{16}$

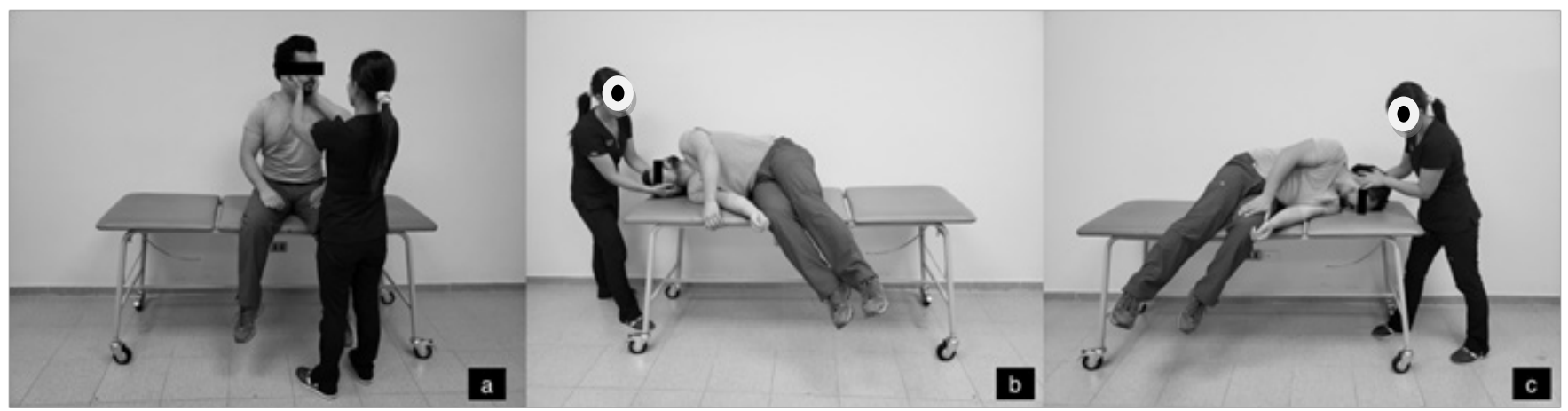

Figure I Maneuver Semont. Example for right posterior semicircular canal.

a: In the first movement, the seated patient b: passes to the right lateral recumbency with the head turned $45^{\circ}$ to the left c: abruptly passes to the left lateral recumbency maintaining the rotation of the head. ${ }^{10}$

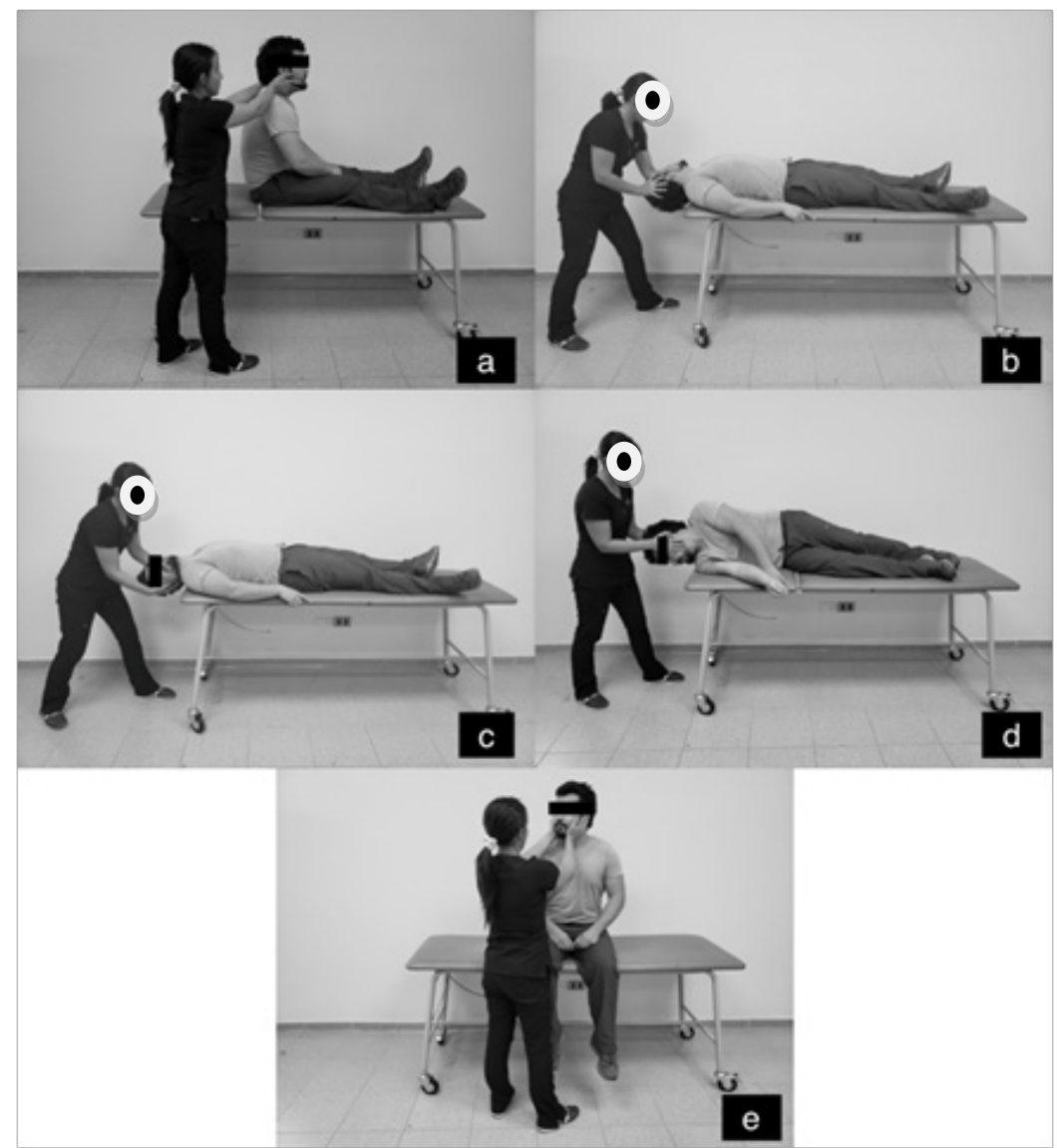

Figure 2 Maneuver Epley. Example for left posterior semicircular canal.

a: Patient is seated, operator behind, oscillator applied. b: Move patient from a sitting to a reclining position. Extend patient's head over the end of the table at $45^{\circ}$ angle c: Tum the patient's head to the opposite side. d: Roll the patient over onto that side. The head is slightly angled while the patient is looking down at the floor. e: While head is kept turned right, patient is brought to sitting position. ${ }^{9,11}$ Finally head is turned forward. 
The Epley maneuver is the one with the greatest evidence in the treatment of BPPV with posterior semicircular canal involvement. When reviewing the literature, all the studies that used Epley maneuver described improvements in BPPV symptomatology, mainly for vertigo, dizziness and nystagmus. André et al. and Ribeiro et al. evaluated quality of life after management of BPPV. They concluded that the Epley maneuver improves patient's quality of life score in elderly, which indicates that this procedure is effective to decrease the impact of the vertiginous symptoms. ${ }^{17,18}$ Similar findings are found after the treatment of people with VPPB in other age groups. ${ }^{6}$

It has also been described that Vestibular Rehabilitation Therapy in elderly with BPPV promotes visual stimuli and eye movements based on the concepts of adaptation and replacement of the vestibuloocular reflex (VOR). ${ }^{19,20}$ The adaptation would occur by performing head movements, in order to reduce the symptoms and stabilize the posture, while the substitution focuses on developing alternative strategies, such as eye movements with slow follow-up. ${ }^{21}$ An example of this is optokinetic exercises, which use virtual reality stimuli where repetitive movement patterns are used and immerses patients to real and challenging environments. ${ }^{22}$ The exercises are aimed at improving the sensation of vertigo, restoring VOR and vestibulospinal gain, reeducating static and dynamic balance, thereby reducing symptoms and reducing the risk of falls in elderly. ${ }^{5}$

Finally, physical therapy for balance and postural control management is included in vestibular rehabilitation. Balance training is a well-established and accepted intervention for persons with vestibular disorders. ${ }^{23}$ It is described as effective in decreasing dizziness and improving functional independence. Moreover, balance training reweighs the sensory adaptive mechanisms in order to prioritize visual and somatosensation, once the training of different systems separately and combined leads the patient to learn to rely on the most appropriate sensory information. ${ }^{23,24}$

Vision is a very important sense for postural control. When the eyes are closed, there are greater postural oscillations due to the inhibition of one of the sensory systems that contribute to postural control. ${ }^{25}$ Therefore, the probability of maintaining stability decreases and, in compensation, the involvement of the proprioceptive and vestibular systems increases. ${ }^{25}$ For this reason, balance training is also performed under both open and closed eyes conditions. It has been pointed out that there are greater effects when training is performed in the absence of visual input. The balance training can significantly improve postural control by promoting anticipatory postural adjustments. ${ }^{26-28}$ The repeated exposure to balance and stability challenges on stable and unstable surfaces results in feedforward adjustments that would recruit the appropriate muscles. ${ }^{26,27}$ Furthermore, the sensitivity of the afferent feedback pathway can be improved with balance training. Also, balance training could stimulate proprioception by inducing peripheral and central neural adaptations. ${ }^{26}$ The proprioceptive system, composed of mechanoreceptors, provides joint position, kinesthesia, and muscle tension information. ${ }^{29}$ The ascending information from muscles (muscle spindles), tendons (Golgi tendon organs), and other mechanoreceptors located in the skin, capsule, and ligaments can be used by the CNS to construct meaningful voluntary movements or to correct perturbations. ${ }^{30}$ Peripheral adaptations that may have occurred because of balance training likely resulted from the repetitive stimulation of the articular mechanoreceptors on both stable and unstable surfaces and in the closed and open eyes conditions.

These adaptations have been indicated as responsible for the improvement of the static and dynamic postural balance. Recommended exercises for balance training include: a) singleleg balance, b) marching in place, c) tandem walk, and d) singleleg squat. The progression of postural balance training consists of performing exercises on: a) stable surfaces with open eyes, b) stable surfaces with closed eyes, c) unstable surfaces with open eyes and d) unstable surfaces with closed eyes. It should be considered that with some elderly people it will not be possible to progress to the final stages of balance training, however, it is recommended to work at least on stable surfaces with eyes closed.

\section{Conclusion}

Vestibular Rehabilitation Therapy included oculomotor exercises, habituation exercises (repeated head and trunk movements), standing and dynamic balance training, along with lower-limb muscles strengthening. Scientific evidence supports Vestibular Rehabilitation Therapy as a safe and effective treatment for management of peripheral vestibular disorders such as BPPV. Therefore, it is necessary to implement a vestibular therapy program in order to contribute to improve the problem presented by elderly from a physiotherapeutic point of view and thus optimize their quality of life.

\section{Acknowledgements}

None.

\section{Conflicts of interests}

The authors of this manuscript have no competing interests.

\section{References}

1. Holmes S, Padgham ND. A review of the burden of vertigo. J clinic nurs. 2011;20(19-20):2690-2701.

2. Evangelista ASdL, Cordeiro ESG, Nascimento GFFd, et al. Speechlanguage-hearing intervention in vestibular rehabilitation with the use of technologies: an integrative literature review. Revista CEFAC. 2019;21(6):e2219.

3. Quitschal RM, Fukunaga JY, Ganança MM, et al. Evaluation of postural control in unilateral vestibular hypofunction. Brazilian journal of otorhinolaryngology. 2014;80(4):339-345.

4. Marchetti GF, Whitney SL, Redfern MS, et al.. Factors associated with balance confidence in older adults with health conditions affecting the balance and vestibular system. Archives of physical medicine and rehabilitation. 2011;92(11):1884-1891.

5. Von Brevern M, Radtke A, Lezius F, et al. Epidemiology of benign paroxysmal positional vertigo: a population based study. $J$ Neurol Neurosurg Psychiatry. 2007;78(7):710-715.

6. Ribeiro KF, Oliveira BS, Freitas RV, et al. Effectiveness of otolith repositioning maneuvers and vestibular rehabilitation exercises in elderly people with benign paroxysmal positional vertigo: a systematic review. Braz J Otorhinolaryngol. 2018;84(1):109-118.

7. Haynes DS, Resser JR, Labadie RF, et al. Treatment of benign positional vertigo using the semont maneuver: efficacy in patients presenting without nystagmus. The Laryngoscope. 2002;112(5):796-801.

8. Silva D, Bastos VH, Sanchez MD, et al. Effects of vestibular rehabilitation in the elderly: a systematic review. Aging Clinical and Experimental Research. 2016;28(4):599-606.

9. Pereira CB, Scaff M. Benign paroxysmal positioning vertigo. Arquivos de neuro-psiquiatria. 2001;59(2B):466-470. 
10. Valenzuela V, Neira P, Viada J. Maniobra de reposición canalítica para el tratamiento del vértigo postural paroxístico benigno. Rev méd Chile. 2000;128(6):619-626.

11. Froehling DA, Bowen JM, Mohr DN, et al.The canalith repositioning procedure for the treatment of benign paroxysmal positional vertigo: a randomized controlled trial. Mayo Clinic Proceedings. 2000;75:695-700.

12. Deveze A, Bernard-Demanze L, Xavier F, et al. Vestibular compensation and vestibular rehabilitation. Current concepts and new trends. Neurophysiologie Clinique/Clinical Neurophysiology. 2014;44(1):49-57.

13. Dos Santos Silva AL, Marinho MRC, de Vasconcelos Gouveia FM, et al. Benign Paroxysmal Positional Vertigo: comparison of two recent international guidelines. Braz J Otorhinolaryngol. 2011;77(2):191-200.

14. Semont A, Freyss G, Vitte E. Curing the BPPV with a liberatory maneuver. Clinical Testing of the Vestibular System. Karger Publishers. 1988;290-393.

15. Epley JM. The canalith repositioning procedure: for treatment of benign paroxysmal positional vertigo. Otolaryngology — Head and Neck Surgery. 1992;107(3):399-404

16. Parnes LS, Price-Jones RG. Particle repositioning maneuver for benign paroxysmal positional vertigo. Annals of Otology, Rhinology \& Laryngology. 1993;102(5):325-331.

17. de Figueiredo Ribeiro KM, Ferreira LMdBM, et al. Positive to negative dix-hallpike test and benign paroxysmal positional vertigo recurrence in elderly undergoing canalith repositioning maneuver and vestibular rehabilitation. Int Arch Otorhinolaryngol. 2016;20(04):344-52.

18. Do Rego André AP, Moriguti JC, Moreno NS. Conduct after Epley's maneuver in elderly with posterior canal BPPV in the posterior canal. $B$ Braz J Otorhinolaryngol 2010;76(3):300-305.

19. Alsalaheen BA, Whitney SL, Mucha A, et al. Exercise prescription patterns in patients treated with vestibular rehabilitation after concussion. Physiotherapy Research International. 2013;18(2):100-108.

20. Cortes Amador SI. Efecto de un programa de fisioterapia vestibular en personas con discapacidad intelectual en proceso de envejecimiento. 2014.
21. Hall CD, Herdman SJ, Whitney SL, Cass SP, et al. Vestibular rehabilitation for peripheral vestibular hypofunction: an evidence-based clinical practice guideline: from the American physical therapy association neurology section. Journal of Neurologic Physical Therapy. 2016;40(2):124.

22. Pavlou M, Bronstein AM, Davies RA. Randomized trial of supervised versus unsupervised optokinetic exercise in persons with peripheral vestibular disorders. Neurorehabilitation and neural repair. 2013;27(3):208-218.

23. Ribeiro KMOBdF, Freitas RVdM, Ferreira LMdBM, et al. Effects of balance vestibular rehabilitation therapy in elderly with benign paroxysmal positional vertigo: a randomized controlled trial. Disability and rehabilitation. 2017;39(12):1198-206.

24. Kristinsdottir EK, Baldursdottir B. Effect of multi-sensory balance training for unsteady elderly people: pilot study of the "Reykjavik model". Disability and rehabilitation. 2014;36(14):1211-1218.

25. Horak FB. Postural orientation and equilibrium: what do we need to know about neural control of balance to prevent falls?. Age and ageing. 2006;35(suppl_2):ii7-ii11.

26. Aruin AS, Ota T, Latash ML. Anticipatory postural adjustments associated with lateral and rotational perturbations during standing. Journal of Electromyography and Kinesiology. 2001;11(1):39-51.

27. Gantchev GN, Dimitrova DM. Anticipatory postural adjustments associated with arm movements during balancing on unstable support surface. Int J Psychophysiol. 1996;22(1-2):117-122.

28. Kanekar N, Aruin AS. Improvement of anticipatory postural adjustments for balance control: effect of a single training session. Journal of electromyography and kinesiology. 2015;25(2):400-405.

29. Peterka RJ, Loughlin PJ. Dynamic regulation of sensorimotor integration in human postural control. Journal of neurophysiology. 2004;91(1):410 423.

30. Hung YJ. Neuromuscular control and rehabilitation of the unstable ankle. World journal of orthopedics. 2015;6(5):434. 